\title{
Reply to the letter by Gaetano Loscocco, Secondary hemophagocytic lymphohistiocytosis, HScore and COVID-19
}

\author{
Akiyoshi Takami ${ }^{1}$ iD \\ Received: 23 May 2020 / Accepted: 26 May 2020 / Published online: 28 May 2020 \\ (c) Japanese Society of Hematology 2020
}

I acknowledge the kind remarks by Dr. Loscocco regarding my interpretation [1] of a recent paper [2] in which the use of both immunosuppressive therapy and the JAK2 inhibitor for hypercytokinemia due to severe COVID-19 has been proposed. I should have stated that "a recent report by Mehta et al. [2] in which all patients with severe COVID-19 should be assessed for secondary hemophagocytic lymphohistiocytosis ( $\mathrm{sHLH}$ ) in the bone marrow and hyperferritinemia using the HScore", because it is now evident that severe COVID-19 can cause sHLH [3, 4]. However, it should be considered that as implied by Dr. Loscocco and in recent reports $[3,5]$, patients with severe COVID-19 may not be in a good enough condition to undertake a bone marrow examination due to their severe condition, thus resulting in difficulty demonstrating hemophagocytosis. Regardless of whether hemophagocytosis is demonstrated or whether the HScore should be used, COVID-19 infection can induce hypercytokinemia associated with marked macrophage activation [6, 7], thus leading to both organ damage and coagulopathy. I would like to reiterate the potential efficacy of low-dose etoposide monotherapy for patients with severe COVID-19 by compensating for the immunoregulator aberration and macrophage activation.

Author contributions AT wrote the manuscript.

Funding There is no funding involved with the manuscript.

Akiyoshi Takami

takami-knz@umin.ac.jp

1 Division of Hematology, Department of Internal Medicine, Aichi Medical University School of Medicine, 1-1

Yazakokarimata, Nagakute 480-1195, Japan

\section{Compliance with ethical standards}

Conflict of interest The author reports no potential conflict of interest.

\section{References}

1. Takami A. Possible role of low-dose etoposide therapy for hemophagocytic lymphohistiocytosis by COVID-19. Int J Hematol. 2020. https://doi.org/10.1007/s12185-020-02888-9.

2. Mehta P, McAuley DF, Brown M, Sanchez E, Tattersall RS, Manson JJ, et al. COVID-19: consider cytokine storm syndromes and immunosuppression. Lancet. 2020;395(10229):1033-4. https:// doi.org/10.1016/S0140-6736(20)30628-0.

3. Prilutskiy A, Kritselis M, Shevtsov A, Yambayev I, Vadlamudi C, Zhao Q, et al. SARS-CoV-2 infection associated hemophagocytic lymphohistiocytosis: an autopsy series with clinical and laboratory correlation. medRxiv. 2020. https://doi. org/10.1101/2020.05.07.20094888.

4. Faguer S, Del Bello A, Abravanel F, Nicolau-Travers ML, Kamar $\mathrm{N}$. Tocilizumab for hemophagocytic syndrome in a kidney transplant recipient with COVID-19. Ann Intern Med. 2020. https:// doi.org/10.7326/L20-0419.

5. Dimopoulos G, de Mast Q, Markou N, Theodorakopoulou M, Komnos A, Mouktaroudi M, et al. Favorable anakinra responses in severe Covid-19 patients with secondary hemophagocytic lymphohistiocytosis. Cell Host Microbe. 2020. https://doi. org/10.1016/j.chom.2020.05.007.

6. Ye Q, Wang B, Mao J. The pathogenesis and treatment of the 'Cytokine Storm' in COVID-19. J Infect. 2020;80(6):607-13. https://doi.org/10.1016/j.jinf.2020.03.037.

7. Huang C, Wang Y, Li X, Ren L, Zhao J, Hu Y, et al. Clinical features of patients infected with 2019 novel coronavirus in Wuhan, China. Lancet. 2020;395(10223):497-506. https://doi. org/10.1016/S0140-6736(20)30183-5.

Publisher's Note Springer Nature remains neutral with regard to jurisdictional claims in published maps and institutional affiliations. 